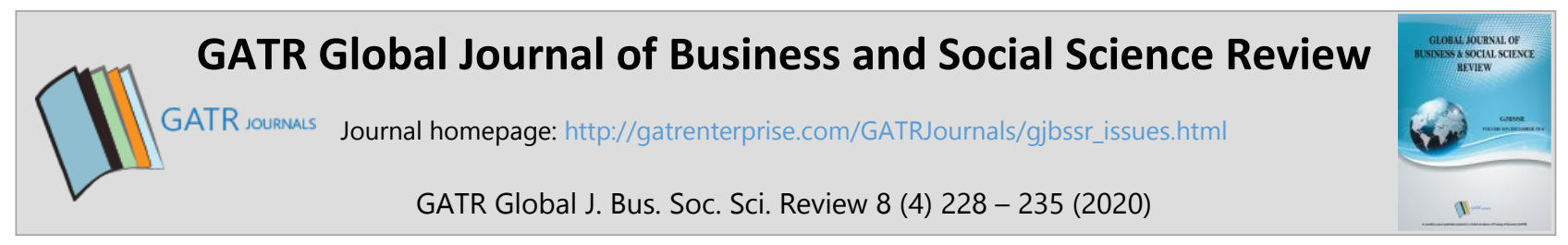

\title{
Enabling Academics to Effectively Use a Learning Management System during a Global Pandemic
}

\author{
Leanri van Heerden ${ }^{1 *}$ \\ ${ }^{1}$ Central University of Technology, Free State, 1 Park Road, 9301, Bloemfontein, South Africa
}

\begin{abstract}
Objective - The 2020 COVID-19 pandemic forced higher education institutions to shift to emergency remote teaching which called for lecturers' learning management system and other online instruction skills to be developed. The issue is that lecturers were forced to work remotely without time to prepare. The purpose of this paper is to propose an online, self-paced short course for lecturers that covered 9 units including; communication tools, video calling, WhatsApp, menu design, learning theory, content creation, online assessment theory, online assessments and the grade centre.

Methodology- A mixed-method research design with participant perspectives was implemented to determine the satisfaction of 125 lecturers who completed the intervention. From 79 who completed the questionnaire with open- and closed-ended questions, it was determined that communication and online assessments were the most sought-after skills and $73.42 \%$ stated that they felt the course met their expectations. The skills were broken down and participants were asked to rate - in a five-point Likert scale - how well they were now able to perform the tasks.

Finding - The results were as follows showing the level four and five (highest) selections; announcements - 83.54\%, send email $-81.01 \%$, content editor $-67.08 \%$, build content (files) $-79.75 \%$, build content (images) $-72.15 \%$, build content (videos) $-70.89 \%$, video conferencing $-58.23 \%$, WhatsApp $-82.28 \%$, course menu design $-73.42 \%$, creating a video in PowerPoint $-58.23 \%$, reflection activities $-44.30 \%$, online tests $-50.63 \%$, online assignments $-50.63 \%$, and managing the grade centre $-48.10 \%$. These results showed that the intervention was successful in quickly and effectively preparing lecturers for online delivery.
\end{abstract}

Type of Paper: Empirical.

JEL Classification: D83, I23.

Keywords: LMS training; e-Learning; Online Instruction; Instructional Design; Blended Learning, Emergency Remote Teaching

Reference to this paper should be made as follows: Heerden, L.V. (2020). Enabling Academics to Effectively Use a Learning Management System during a Global Pandemic, GATR Global J. Bus. Soc. Sci. Review, 8(4): $228-235$. https://doi.org/10.35609/gjbssr.2020.8.4(4)

\section{Introduction}

The global pandemic of COVID-19 introduced new and unique challenges in universities and other education institutions across South Africa.

\footnotetext{
* Paper Info: Revised: August 19, 2020

Accepted: December 31, 2020

* Corresponding author: Leanri van Heerden

E-mail: 1vheerden@cut.ac.za

Affiliation: Centre for Innovation in Learning and Teaching, Central University of Technology, South Africa
} 
On 23 March 2020, President Cyril Ramaphosa announced a national lockdown level 5 would start on 26 March 2020 (Department of Health, 2020). A three-day head start for a three-week lockdown was a logistical nightmare for even the most technology-driven universities. All staff were sent home with only enough time to grab their office plants and laptops and no idea how they were going to move forward.

The issue with staff and students all working from home is that the lecturers working at the Central University of Technology (CUT), being primarily a face-to-face delivery university, were completely unprepared for moving their traditional face-to-face and blended approaches to completely online. In their study, Mogeni, Ondigi and Mufo (2020) found that most of the investigated teachers were not empowered enough to deliver instruction fully online and either needed to be retrained, receive further specialised training or be trained completely from scratch. A lack of confidence in the delivery mode of instruction will cause even the most knowledgeable subject specialist to fail in their task. At the CUT lecturers needed a way of quickly acquiring the necessary skills to deliver their content and assessments on the institution Learning Management System (LMS).

The aim of this paper is to measure participant perspectives of an emergency intervention to facilitate the process of online delivery skills acquisition quickly and via an online platform. To ensure relevant results, a systematic process of designing an intervention and recording participant perspectives is necessary.

This paper will firstly underpin the research with a literature review, then take a look at the methods used to drive the research, briefly discuss the results and findings, and lastly conclude by exploring the implications and significance of the research for the use of higher education institutions for emergency LMS training.

\section{Literature Review}

Blended learning is a blend between using both online technologies for instruction and face-to-face teaching. Hrastinski (2019) reviewed current definitions and found that the key words are a "combination of face-to-face instruction with computer-mediated instruction" but also that the practice should be a "thoughtful integration" of the two. Thoughtful, meaning that blended should seamlessly move between the two delivery modes and not just be repetition or the online platform only serve as a resource storage space (Garrison \& Kanuka, 2004). The online component should be used to communicate and engage as much as if the student were in the classroom.

Information communication technologies (ICTs) have become a must have for higher education institutions, which is why most have invested in LMSs to facilitate the process. An LMS is a software application used to facilitate online education, that replaces or enhances face-to-face learning (Walker, 2017). Dziuban, Graham, Moskal, Norberg, \& Sicilia (2018) state that the adoption of blended learning has been so widespread that it has become the "new traditional normal". The advantage of a blended learning approach is that when the lecturers are slow in the technology uptake the students are still seen face-to-face on a regular basis. It is the responsibility of the institution to support its lecturers in mastering needed education technologies.

To enable lecturers to learn educational technology skills, and more importantly apply the right technology needed for the content, institutions look to their e-learning and educational technology units to lead the way. Coined by Jameson (2013) as e-Leadership this process should be driven by sound research as well as instructional designers staying on top of emerging technologies. As e-learning and educational technology is by no means a new field it is important for instructional designers to selectively adopt and train in the most suited technologies for the discipline, institution and student demographic. Having a comprehensive and ever updating training program that promotes self-exploration of technology will serve an institution well if physical contact suddenly becomes prohibited.

Emergency remote teaching (ERT) is the sudden and temporary shift in instructional delivery due to unforeseen/crisis circumstances like the COVID-19 pandemic of 2020. Temporary is the "key word" here as ERT is not planned and shifts to remote teaching only until the crisis is over when it will most likely resume

GATR Global J. Bus. Soc. Sci. Review 8 (4) 228 -235 (2020) 
its former delivery mode (Hodges, Moore, Lockee, Trust, \& Bond, 2020). ERT will most likely be implemented with very short notice giving lecturers very little face-to-face time to prepare themselves and students for the virtual alternatives (Czerniewicz, 2020). In such a case, the institution's e-learning unit needs a quick and effective way, that is online, to train a large number of lecturers in the use of the LMS.

\subsection{Emergency remote teaching}

Emergency remote teaching (ERT) is the sudden and temporary shift in instructional delivery due to unforeseen/crisis circumstances like the COVID-19 pandemic of 2020. Temporary is the "keyword" here as ERT is not planned and shifts to remote teaching only until the crisis is over when it will most likely resume its former delivery mode (Hodges, Moore, Lockee, Trust, \& Bond, 2020). ERT will most likely be implemented with a very short notice giving lecturers very little face-to-face time to prepare themselves and students for the virtual alternatives (Czerniewicz, 2020). In such a case, the institution's e-learning unit needs a quick and effective way, that is online, to train a large number of lecturers in the use of the LMS.

\section{Research Methodology}

This paper employed a mixed method using participant perspectives. The mixed-method enabled qualitative and quantitative data to be collected in the form of open- and closed-ended questions respectively being asked in a questionnaire (Gibson, 2017). Participant perspectives is an exploratory research method that allows the researcher to open a new research area and delve into the experience of the user to further improve an intervention (De Vos, Strydom, Fouche, \& Delport, 2011). Getting feedback from the users of an intervention - focusing on outcomes reached - helps the designer improve the instruction with each iteration.

Participants were asked to complete a 9-unit, self-paced instructional online short course on Blackboard, which is the LMS used by CUT. The short course covered the following topics; communication tools, video calling, WhatsApp, course menu design, learning theory, content creation, online assessment theory, online assessments and the grade centre. Review status was used to track participant progress.

After completing the short course, participants were asked to complete an online questionnaire focusing on skills acquired. Open- and closed-ended questions were asked, with the quantitative data collected using a five-point Likert scale on the satisfaction rate from the users on their new skills. The target population of the paper was all academic staff interested in participating in the course and of the 342 who enrolled 125 completed all 9 units. Of this number 79 completed the online feedback questionnaire.

\section{Results}

Participant perspectives were obtained through an online questionnaire using QuestionPro. Eighteen questions were asked of which 3 open-ended and 3 closed ended will be discussed here for their relevance to the aim of this paper, which is skills acquisition.

\subsection{Qualitative data}

The three qualitative, open-ended questions were asked to determine firstly the participants' expectations of the course, secondly what they felt the course did well and lastly what they would like to see improved in a future iteration.

When asked "What skills did you want to learn by doing this course?" the most common responses related to communication with students, creating digital content and online assessment. One participant mentioned all by stating "Communication via online platforms such as conducting online contact sessions with students, creating WhatsApp groups and creating online assessments and tests on Blackboard." A few participants also mentioned the wish for better interface design with one saying: "Making my online learning platform more user friendly for the students." 
To determine what was working in the course, participants were asked "What have been the best aspects of the course for you?" to which most responded that having all the information needed in a single course was helpful with one response indicating that "it touched on most of the information needed". Some participants also mentioned that the course was well designed with one stating: "The layout is very easy to navigate".

To determine what was working in the course, participants were asked "What have been the best aspects of the course for you?" to which most responded that having all the information needed in a single course was helpful with one response indicating that "it touched on most of the information needed". Some participants also mentioned that the course was well designed with one stating: "The layout is very easy to navigate".

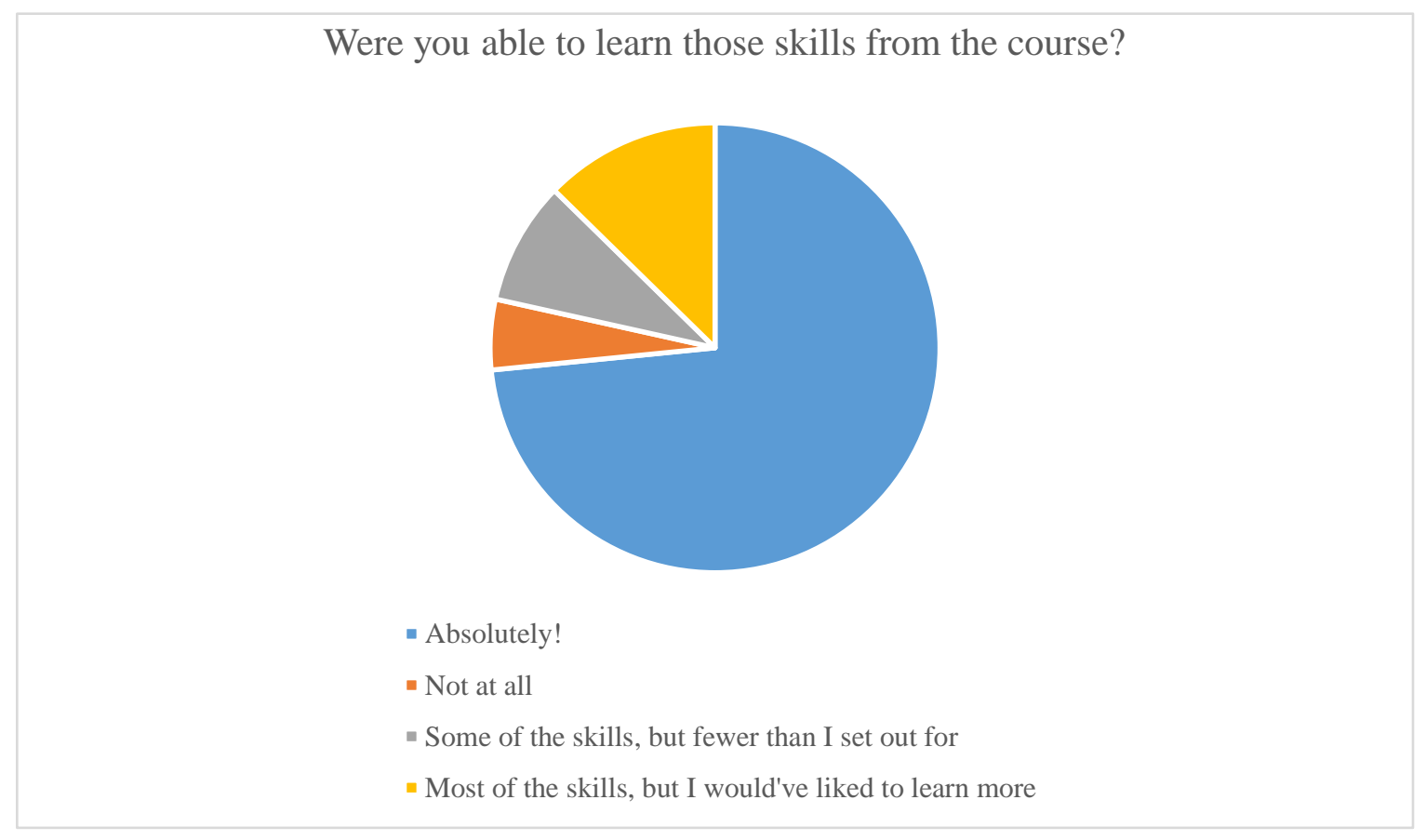

Figure 1. Pie-chart of results when participants were asked "Were you able to learn those skills from the course?" referring to their pre-course expectations.

The final qualitative data was collected by asking "What in your opinion needs improvement?" to expose possible enhancements for the course in future. Although most participants could not add any suggestions for future improvements, some suggestions may prove useful like one asking for "activities and feedback for each section to check how well the content was understood". Another point of interest mentioned was that participants would like some practical experience in the form of blank practice space to try out the new skills immediately.

\subsection{Quantitative data}

The questionnaire started by asking participants about their expectations of the short course and to share some of the skills they had hoped to learn as mentioned under the previous heading. This question was followed by a question asking them whether they were able to acquire these expected skills by working through the short course. A promising $73.42 \%$ of participants answered "Absolutely!" as shown in Figure 1 below. 
The different skills instructed in the course and subsequently questioned in the questionnaire will be grouped here as communication, facilitation and assessment skills. Under communication skills creating announcements, sending email and managing WhatsApp groups were covered. Facilitation included Zoom video conferencing, building and editing content, menu design, and creating video from PowerPoint slides. Finally, assessment skills were questioned with reflection activities, online tests and assignments.

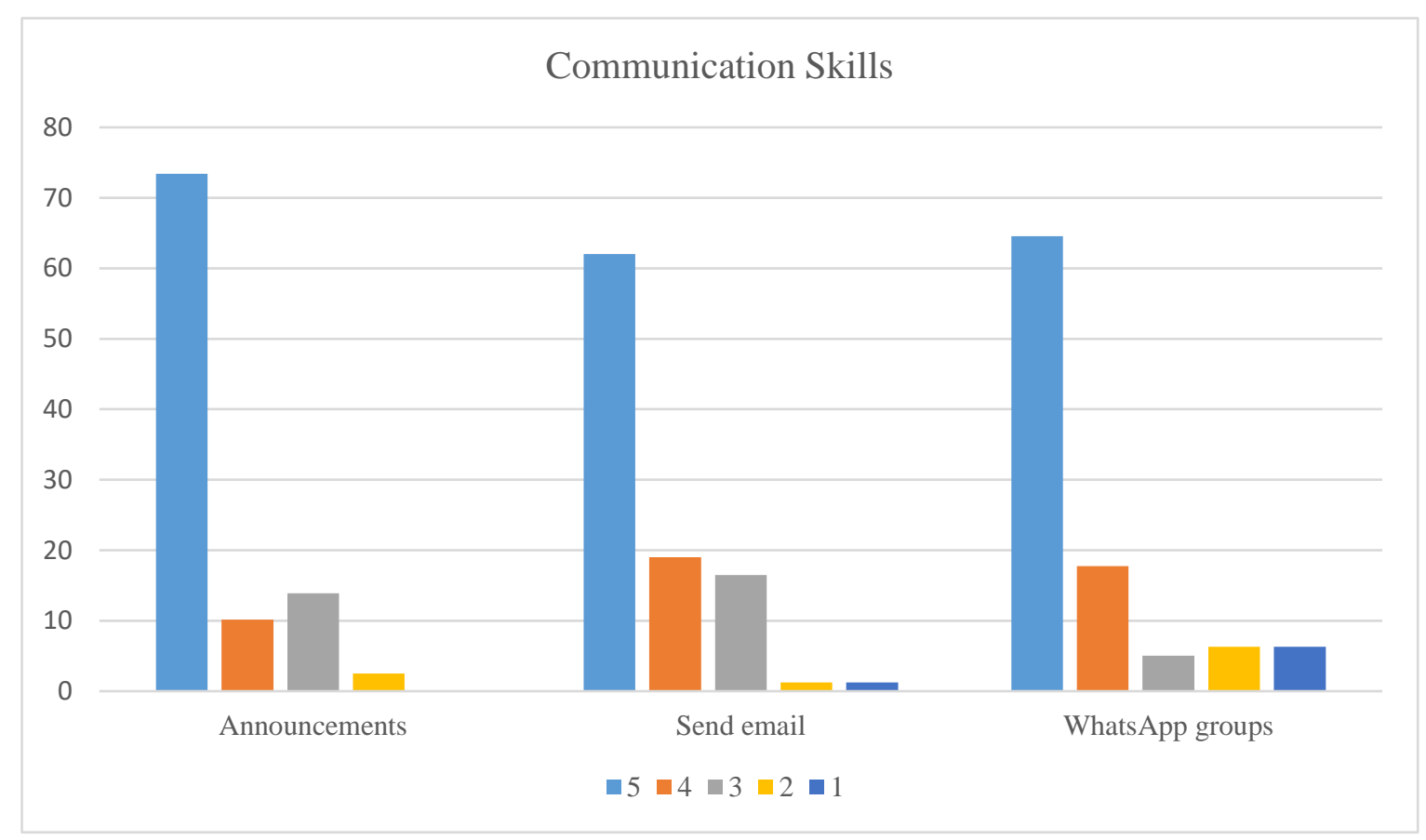

Figure 2. Participants' feedback on communication skills acquired.

The above chart (fig.2) indicates that the majority of participants were satisfied to very satisfied with the communication skills they acquired indicating 4 and 5 on the Likert scale respectively. For sending announcements $83.54 \%(73.42 \%=5$ and $10.13 \%=4)$ of participants indicated satisfaction. When sending emails through the LMS $81.01 \%(62.03 \%=5$ and $18.99 \%=4)$ felt they mastered the skill and $82.28 \%$ $(64.56 \%=5$ and $17.72 \%=4)$ that they can create and manage WhatsApp groups 


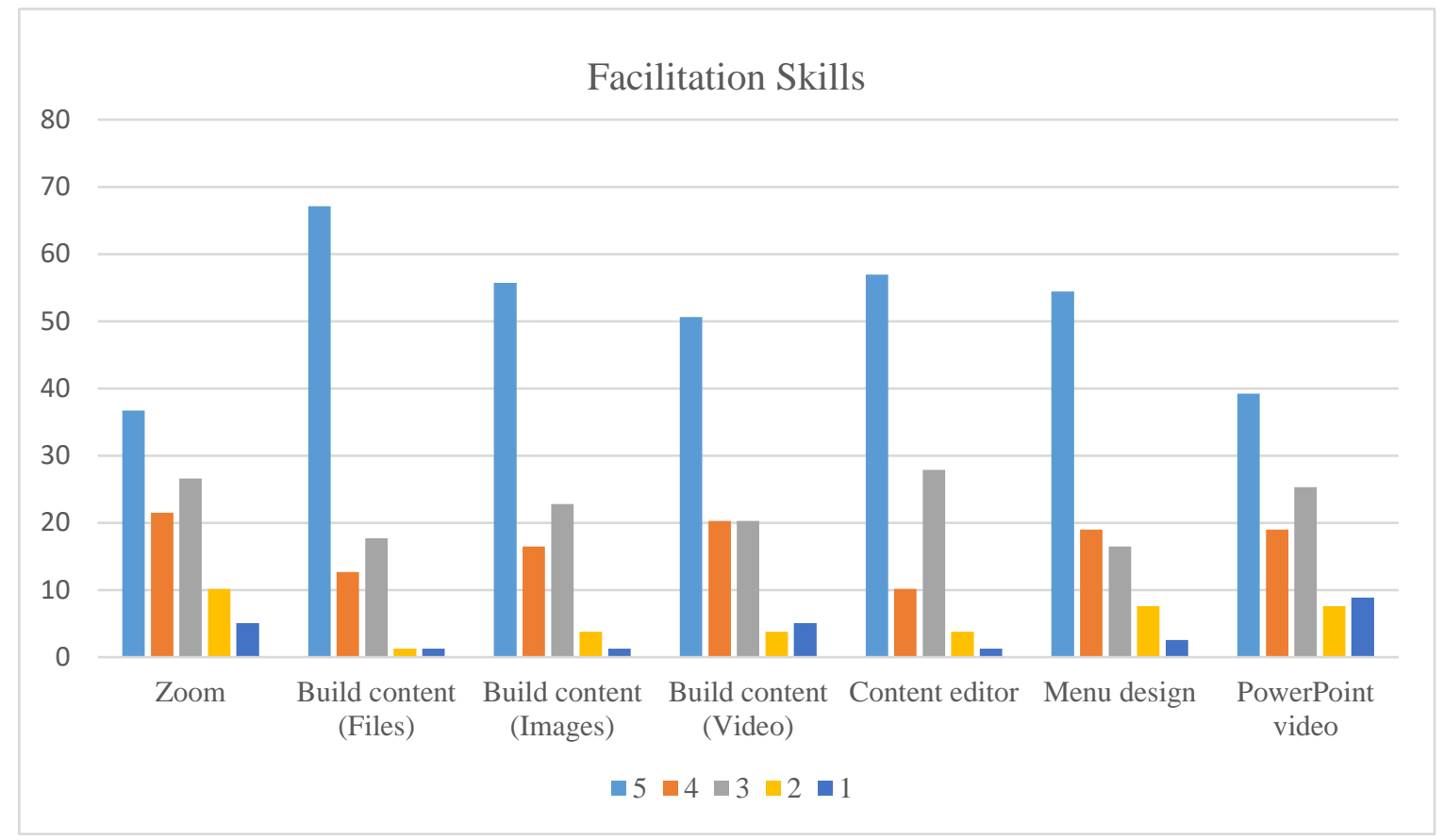

Figure 3. Participants' feedback on facilitation skills acquired.

Figure 3 shows that participants' satisfaction with facilitation skills were highest with building content. Of these, files received the highest rates with $79.75 \%(67.09 \%=5$ and $12.66 \%=4)$, images at second with $72.15 \%$ $(55.7 \%=5$ and $16.46 \%=4)$ and then videos with $70.89 \%(50.63 \%=5$ and $20.25 \%=4)$. Both Zoom video conferencing and the content editor skills had a high neutral (3) satisfaction rate with $26.58 \%$ and $27.85 \%$ respectively which is less than ideal even though the majority was still satisfied with these skills at $58.23 \%$ $(36.71 \%=5$ and $21.52 \%=4)$ and $67.09 \%(56.96 \%=5$ and $10.13 \%=4)$ respectively.

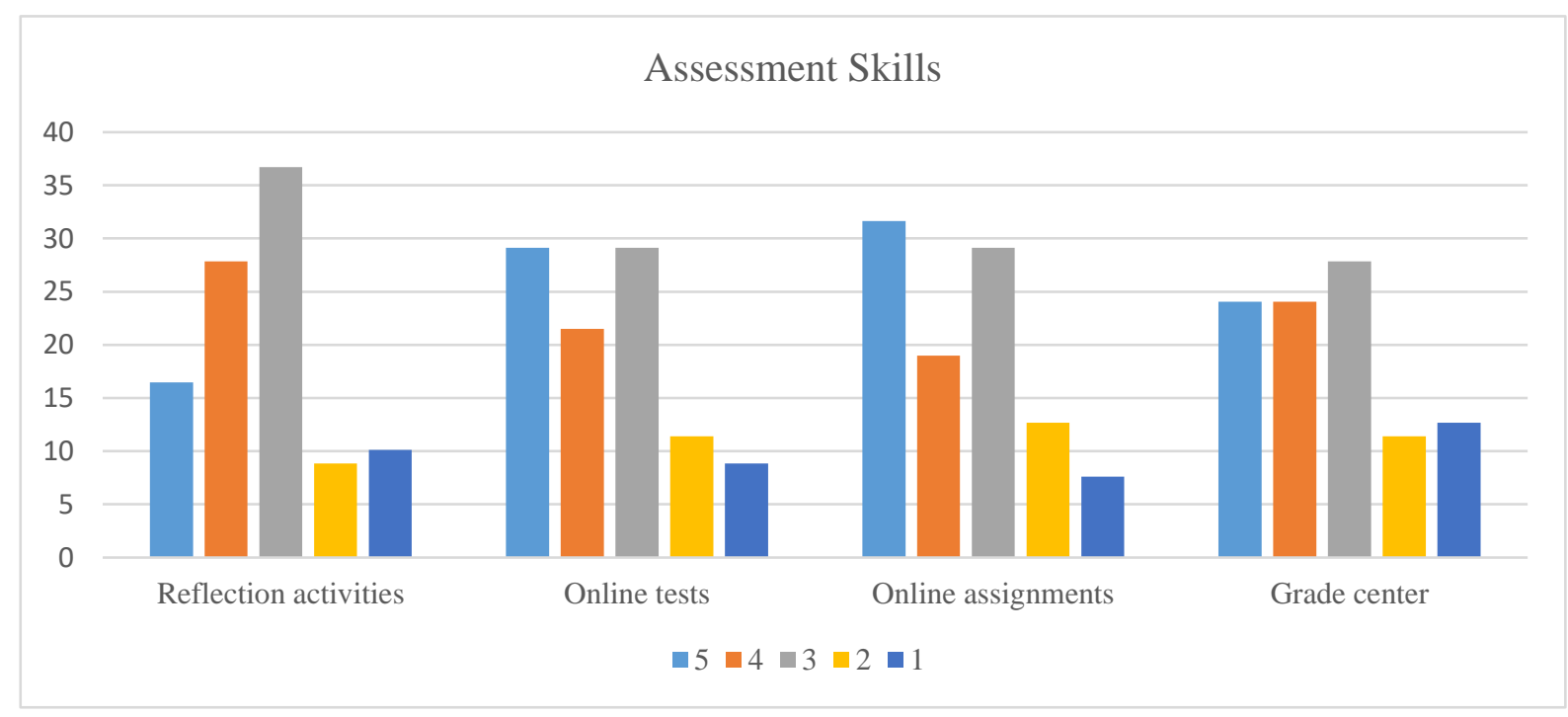

Figure 4. Participants' feedback on assessment skills acquired.

Of the three groups, the assessment skills proved to be the most difficult to master as seen in Figure 4. All four skills listed under assessment skills still received positive feedback with online tests and assignment

GATR Global J. Bus. Soc. Sci. Review 8 (4) 228 -235 (2020) 
being mastered by the majority with $50.63 \%(29.11 \%=5$ and $21.52 \%=4)$ and $50.63 \%(31.65 \%=5$ and $18.99 \%=4)$ respectively. The grade center skills

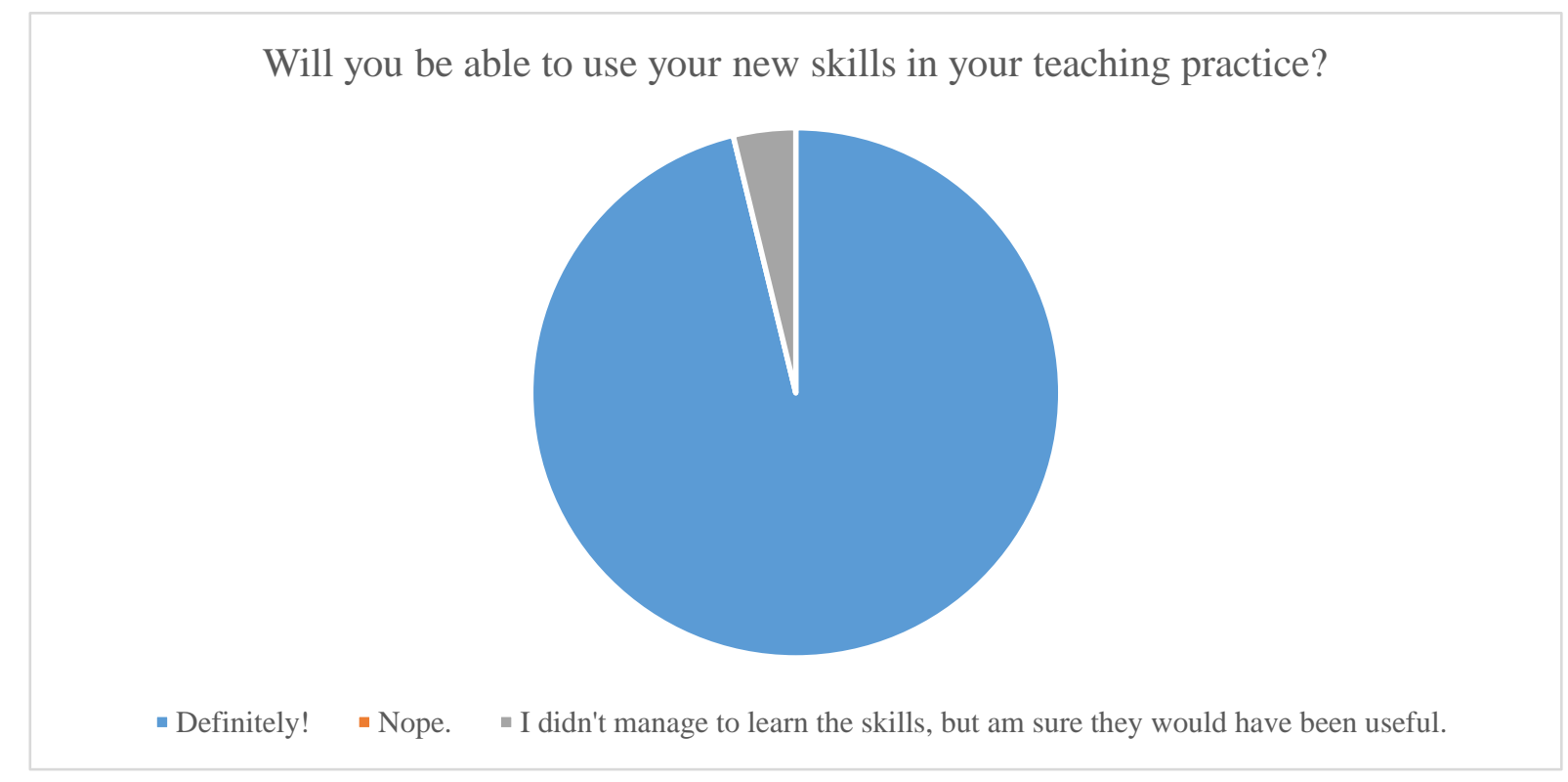

Figure 5. Participants' response on using the newly acquired skills in their teaching practice.

fared the worst with $24.05 \%(12.66 \%=1$ and $11.39 \%=2)$ not being satisfied with these skills' acquisition however the majority was still satisfied with $48.10 \%(24.05 \%=5$ and $24.05 \%=4)$.

Finally, when asked "Will you be able to use your new skills in your teaching practice during the lockdown?" a near-perfect score of $96.20 \%$ answered "Definitely!".

\section{Discussion}

The results from the participants' perspectives on their skills acquisition after completing the course show that such an intervention can quickly and effectively train lecturers on the use of the LMS for ERT. The $72.42 \%$ of participants who felt that the course met their expected outcomes show that the skills addressed in the course are what is needed by the lecturers. All of the skills received majority positive ratings which indicate that the course provides enough instruction however, the lower ratings for the assessment skills show those skills as an area that needs improvement in the next iterations. When institutions are forced to suddenly move to online instruction, these are the online delivery skills needed by lecturers to ensure student success.

For institutions that deliver face-to-face or blended instruction, a sudden state of emergency where lecturers and students can't come to campus can have alarming consequences. If more students than usual cannot complete a year successfully, the next year will suffer from overpopulated classes, facility shortages and most importantly the institution not receiving enough subsidy from government to finance the next year.

As a perspective paper, these results can only show how participants felt regarding their skills acquisition and not if the new skills were implemented with any degree of success. A recommendation can be made to implement a pretest-posttest design study focusing on the skills however, it will be important to note that a single group pretest-posttest may not yield the truest validity (Knapp, 2016) and designing a test with a control group will mean the delivery of the course will have to be changed from asynchronous (self-paced) to synchronous to avoid history and maturation threats to the validity of the results. An evaluation of the participants online delivery after completing the course can also be carried out to determine whether the skills, they felt they mastered, were used in a way that benefits the student. 


\section{Conclusion}

The aim of this paper was to measure participant perspectives of lecturers' online delivery skills acquisition during an online short course. This intervention was needed as the COVID-19 lockdown measures meant lecturers had to suddenly move their teaching practice completely online. Most lecturers having practised a mainly blended approach up to this point were not equipped for online class delivery and the e-learning unit had to implement emergency LMS training to prepare them.

The short course intervention produced favourable results for skills acquisition and seeing as it is online and self-paced, little input was necessary from the overwhelmed e-learning unit. Not only could lecturers learn the new skills from home and in their own time, but also experience the online environment as a student which is a valuable experience for troubleshooting when students encounter technical problems.

This type of emergency LMS training intervention can prepare lecturers for a sudden shift in the academic environment quickly, effectively and more importantly with no extra human resources from the supporting elearning unit. With lecturers projecting confidence in the technology, students will also feel more encouraged to participate and work through the lockdown with the courage to know that they can excel in their studies and reach the next level.

\section{References}

Czerniewicz, L. (2020, March 15). What we learnt from "going online" during university shutdowns in South Africa. Retrieved from PhilonEdTech: https://philonedtech.com/what-we-learnt-from-going-online-during-universityshutdowns-in-south-africa/

De Vos, A. S., Delport, C. S. L., Fouché, C. B., \& Strydom, H. (2011). Research at grass roots: A primer for the social science and human professions. Van Schaik Publishers.

Department of Health. (2020, September 19). COVID-19 South African Online Portal. Retrieved from SA Coronavirus: https://sacoronavirus.co.za/

Dziuban, C., Graham, C. R., Moskal, P. D., Norberg, A., \& Sicilia, N. (2018). Blended learning: the new normal and emerging technologies. International Journal of Educational Technology in Higher Education, 15(1), 3.https://doi.org/10.1186/s41239-017-0087-5

Garrison, D. R., \& Kanuka, H. (2004). Blended learning: Uncovering its transformative potential in higher education. The internet and higher education, 7(2), 95-105.https://doi.org/10.1016/j.iheduc.2004.02.001

Gibson, C. B. (2017). Elaboration, generalization, triangulation, and interpretation: On enhancing the value of mixed method research. Organizational Research Methods, 20(2), 193-223. https://doi.org/10.1177/1094428116639133

Hodges, C., Moore, S., Lockee, B., Trust, T., \& Bond, A. (2020). The difference between emergency remote teaching and online learning. Educause Review, 27.

Hrastinski, S. (2019). What do we mean by blended learning?. TechTrends, 63(5), 564-569. https://doi.org/10.1007/s11528-019-00375-5

Jameson, J. (2013). e-L eadership in higher education: The fifth "age" of educational technology research. British Journal of Educational Technology, 44(6), 889-915.https://doi.org/10.1111/bjet.12103

Knapp, T. R. (2016). Why is the one-group pretest-posttest design still used? https://doi.org/10.1177/1054773816666280

Mogeni, M. J., Ondigi, S. R., \& Mugo, B. C. (2020). Extent of Teacher Preparedness and Capacity to Implement Information and Communication Technologies in the Nepad E-Schools, Kenya. African Journal of Education and Practice, 6(6), 1-28. https://doi.org/10.47604/ajep.1138

Walker, D. S., Lindner, J. R., Murphrey, T. P., \& Dooley, K. (2016). Learning management system usage. Quarterly Review of Distance Education, 17(2), 41-50. 